\title{
VIOLÊNCIA ESCOLAR NA PERSPECTIVA DE ADOLESCENTES: POTENCIALIDADES PARA O ENFRENTAMENTO
}

Ethel Bastos da Silva ${ }^{1}$, Marta Cocco da Costa ${ }^{2}$, Milene dos Santos ${ }^{3}$, Alice do Carmo Janh ${ }^{4}$

\begin{abstract}
RESUMO: Estudo de abordagem qualitativa, exploratório-descritivo, teve por objetivo conhecer e analisar as concepções de violência escolar e ações potenciais de enfrentamento, na perspectiva de adolescentes. A pesquisa foi realizada em duas escolas públicas com 13 jovens de 16 a 18 anos, que cursavam a segunda série do ensino médio. Os dados foram coletados por meio de entrevista semiestruturada, no mês de agosto de 2010. A análise foi realizada mediante modalidade temática, da qual emergiram dois eixos temáticos: Violência na escola-atitude "naturalizada" nas relações entre adolescentes, evidenciando-se que a violência escolar está relacionada à agressão física e verbal, e Ações de enfrentamento da violência: possibilidades de intervir. Os adolescentes julgam que o acesso ao estudo e ao conhecimento são formas para enfrentar a violência, mas consideram difícil esse enfrentamento. Os achados deste estudo reforçam a necessidade de um trabalho interdisciplinar e intersetorial para fortalecer o já existente.
\end{abstract}

DESCRITORES: Enfermagem em saúde comunitária; Saúde do adolescente; Violência.

\section{VIOLENCIA ESCOLAR EN LA PERSPECTIVA DE ADOLESCENTES: POTENCIALIDADES PARA EL AFRONTAMIENTO}

RESUMEN: Estudio de abordaje cualitativo, exploratorio descriptivo. Su objetivo fue conocer y analizar las concepciones de violencia escolar y acciones potenciales de afrontamiento, en la perspectiva de adolescentes. La investigación fue realizada en dos escuelas públicas con 13 jóvenes de 16 a 18 años, que estaban en segunda serie de la enseñanza media. Los datos fueron recogidos por medio de entrevista semiestructurada, en el mes de agosto de 2010. El análisis fue realizado por la modalidad temática, de la cual resultaron dos ejes temáticos: Violencia en la escuela - actitud "naturalizada" en las relaciones entre jóvenes, evidenciándose que la violencia escolar está relacionada a la agresión física y verbal, y Acciones de afrontamiento de la violencia: posibilidades de intervenir. Los adolescentes juzgan que el acceso al estudio y al conocimiento son formas para afrontar la violencia, pero consideran difícil ese afrontamiento. Los resultados de este estudio refuerzan la necesidad de un trabajo interdisciplinar e intersectorial para fortalecer aquello ya existente. DESCRIPTORES: Enfermería en salud comunitaria; Salud del adolescente; Violencia.

\section{SCHOOL VIOLENCE IN THE VIEW OF ADOLESCENTS: POSSIBILITIES FOR ITS CONFRONTATION}

\begin{abstract}
This exploratory-descriptive study, with a qualitative approach, aimed to investigate and analyze the concepts of school violence and possible actions for confronting it in the view of adolescents. The research was undertaken in state schools with 13 young people aged from 16 to 18 years old, who were attending the second grade of senior high school. The data were collected through semi-structured interviews, in August 2010. The analysis was undertaken through the thematic modality, from which emerged two thematic axes: Violence in the school-a "naturalized" attitude in the relationships among adolescentes, evidencing that school violence is related to physical and verbal aggression, and Actions for confronting the violence: possibilities for intervening. The adolescents consider access to study and to knowledge to be ways for confronting the violence, but consider this confrontation to be difficult. This study's findings reinforce the need for interdisciplinary and intersectorial work to strengthen that which already exists. DESCRIPTORS: Community health nursing; Adolescent health; Violence.
\end{abstract}

${ }^{1}$ Enfermeira. Doutora em Ciências. Professora da Universidade de Santa Maria. Palmeira das Missões-RS-Brasil ${ }^{2}$ Enfermeira. Doutora em Enfermagem. Professora da Universidade de Santa Maria. Palmeira das Missões-RS-Brasil

${ }^{3}$ Enfermeira. Mestre em Enfermagem. Doutoranda em Ciências. Professora da Universidade de Santa Maria. Palmeira das MissõesRS-Brasil

${ }^{4}$ Enfermeira. Palmeira das Missões.

Autor correspondente:

Recebido: $18 / 03 / 2013$

Ethel Bastos da Silva

Aprovado: 05/12/2013

Universidade Federal de Santa Maria

Rua Andrade Neves, 555 - 98025-810 - Cruz Alta-RS-Brasil

E-mail: ethelbastos@hotmail.com

Cogitare Enferm. 2014 Jan/Mar; 19(1):20-6 


\section{INTRODUÇÃO}

Em todo mundo a violência escolar é debatida e pesquisada por aparecer como tema cotidiano da sociedade. O que chama a atenção é que essa problemática se torna visível a partir de acontecimentos fatais, por exemplo, morte ou incidentes mais graves nos arredores e dentro das escolas, muitas vezes mascarando outros tipos de violência que acontecem nos ambientes escolares e nos espaços que os cercam ${ }^{(1)}$. A sociedade, em geral, está preocupada com esse fenômeno que afeta o cotidiano de professores, alunos, diretores e funcionários, refletindo-se nos relacionamentos, na qualidade de ensino, no desempenho dos estudantes e seu interesse pelo estudo ${ }^{(2)}$.

A violência sofrida, ou praticada, nas escolas se manifesta de forma distinta e sofre influências das condições de extrato social, tipo de instituição, cultura e gênero. A humilhação é o tipo de violência mais sofrida, seguida de furto, ameaça e destruição de pertences; a humilhação e furtos estão presentes nas escolas privadas e as agressões e depredações presentes nas escolas públicas; nas escolas localizadas em áreas de intensos conflitos violentos, a arma de fogo é instrumento de violência ${ }^{(3)}$.

A concepção de violência na escola é evidenciada de forma diferente pelos atores envolvidos; professores, alunos e funcionários têm concepções distintas do problema, talvez porque estejam profundamente ligadas às singularidade de cada grupo ${ }^{(4)}$. A violência surge de problemas que fazem parte do dia a dia e só pode ser resolvida se for pensada de maneira coletiva ${ }^{(2)}$; ainda assim, há concepções de jovens estudantes e professores que são convergentes, por exemplo, o diálogo, o uso de normas de conduta e punições para transgressões - prática necessária para prevenir atitudes violentas na escola, desde que adotadas com justiça e equidade $^{(5)}$. Outro aspecto em comum identificado nos estudos é a maior interação entre a escola e a família, e a introdução de novas estratégias para o enfrentamento da violência, considerando-se que essas duas instituições encontram-se em lugares privilegiados para a ação ${ }^{(6)}$.

Tem-se observado investimentos por parte do setor saúde e educação no combate à violência nas escolas com a adoção das políticas em estados e municípios; para realizar ações é preciso maior interação entre esses e outros setores. As ações só podem ser planejadas se houver conhecimento da real violência vivida nas escolas e se forem identificadas as possibilidades de ações de intervenção preventiva e de promoção, considerando-se que a escola é um local complexo e dinâmico. Assim, para propor intervenções é necessário investigar o que pensam e o que vivem aqueles que fazem parte dela, especialmente os jovens ${ }^{(7)}$.

É nesse contexto que se busca conhecer e analisar as concepções de violência escolar e ações potenciais de enfrentamento, na perspectiva dos adolescentes, em escolas públicas, a fim de fomentar o planejamento de estratégias de intervenção locais e municipais relativas a essa problemática na perspectiva intersetorial.

\section{MÉTODO}

A partir da problemática e do objetivo desta pesquisa optou-se pelo estudo exploratório-descritivo, e com abordagem qualitativa afim de incorporar a questão do significado e da intencionalidade como inerentes aos atos, às relações e às estruturas sociais, sendo estas últimas tomadas tanto no seu advento quanto na sua transformação como construções humanas significativas ${ }^{(8)}$.

O estudo foi desenvolvido com duas das nove turmas do segundo ano do Ensino Médio de escolas públicas do Município de Palmeira das Missões - Rio Grande do Sul, turmas sugeridas pela direção da escola por serem alunos com comportamentos considerados inadequados. Os participantes eram adolescentes e os critérios de inclusão foram: ter idade entre 16 e 18 anos, cursar a $2^{\mathrm{a}}$ série do Ensino Médio, regularmente matriculado, presente na escola por ocasião da coleta de dados, e que consentisse em participar do estudo por meio do Termo de Consentimento Livre e Esclarecido assinado por si próprio, ou pelos seus representantes legais no caso de jovens menores de idade. Os critérios de exclusão foram: estar afastado das atividades escolares por motivo de doença. Os participantes da pesquisa totalizaram 13 adolescentes, três do sexo masculino e 10 do sexo feminino.

A coleta de dados foi realizada, por meio de entrevista semiestruturada, em agosto de 2010, norteada por um roteiro-guia para as entrevistas, dividido em duas partes. A primeira contendo dados sociodemográficos e a segunda com questões abertas referentes ao problema de pesquisa.

Os encontros para a realização das entrevistas foram previamente agendados com cada adolescente e realizados em uma sala apropriada da escola para manter um diálogo com garantia da privacidade. Antes de iniciar, as participantes receberam informações e esclarecimentos sobre a pesquisa e assinaram o Termo de Consentimento Livre e Esclarecido, em duas vias, 
sendo que uma ficou com o entrevistado e a outra com o pesquisador. Para os alunos menores de 18 anos foi entregue o TCLE para os pais assinarem e conforme os devolviam, agendava-se a entrevista. As entrevistas foram gravadas em MP3, após a autorização do participante, com a finalidade de registrar integralmente o conteúdo e assegurando material fidedigno e, posteriormente, transcritas na íntegra para a fase de análise.

Para a análise dos dados optou-se pela Análise de Conteúdo, do Tipo Temática ${ }^{(8)}$ e das questões norteadoras emergiram dois eixos temáticos: Violência na escola - atitude naturalizada nas relações entre os adolescentes e Ações de enfrentamento da violência: possibilidades de intervir.

Este estudo foi realizado de forma a respeitar as normas éticas de pesquisa; a coleta dos dados foi realizada após a aprovação do Comitê de Ética da Universidade Federal de Santa Maria, mediante o Protocolo número 23081.009915/2010-11. Os alunos foram identificados por códigos; a letra J para o termo jovem, seguida de A para uma das escolas e B para a outra, e o número sequencial das entrevistas.

\section{RESULTADOS}

O primeiro eixo temático Violência na escola - atitude naturalizada nas relações entre os adolescentes revela manifestação usual nas relações dos adolescentes, decorrente de discussões que poderiam ser resolvidas pelo diálogo, causando estranhamento e desconforto nesse grupo que considera ruim essa forma de comportamento, conforme se constata nas falas:

[...] uma coisa ruim, né, que acontece que brigam por qualquer coisa. E a gente, por exemplo, às vezes, só por um esbarrão. (JB1)

[...] agenteescuta, a gentemesmopratica [faz], e[a violência] fisica existe brigas, isto éaté uma coisa mais normal. (JA1)

A banalização da violência é caracterizada pelo uso da agressão física, como forma de solucionar conflitos de interesses, entre pessoas ou grupos. Os adolescentes resolvem seus problemas de relacionamento dentro e fora da escola, muitas vezes por meio da violência. As falas a seguir confirmam:

[...] nós tavajogando bola como sempre, daícomo sempre tem uns que se acham. Como é normal daí o cara ir lá, faz a falta, dai deu briga. Deu briga, mas é só a única. (JB7)
[...] quando entrei na escola ele tava ali, eu não sabia quem era e ele simplesmente chegou me batendo, dai eu bati nele. Dai veio outros alunos amigo meu, e separaram. É que tinha uma guria nova que veio na escola, ela era bem bonita, ajeitada, maior de idade já. E dai ela disse, não, eu sou solteira. ...aí a gente foi na casa da outra colega, dai ela tava lá, eu tava lá, e a gente ficou. [...] só que eu não sabia que ela era casada, se não eu não tinha me envolvido. (JB3)

Observa-se, neste estudo, que as brigas entre os adolescentes são indiferentes à questão de gênero e as causas são a disputa de poder em alguma área social afetiva, por exemplo, namoro ou amizade (ciúmes de namorado e ex-namorado) e jogos que acontecem no interior e fora da escola. As falas dos entrevistados comprovam o que se constatou neste estudo:

[...] eu já vi. As meninas brigando, os guris. Tipo de tapa e puxão de cabelo. O motivo é porque umas debocham das outras e por causa de menino. (JB1)

[...] aqui na escola aconteceu esses dias, umas guria elas se pegaram no laço por causa de pouca coisa, briga entre namorados que fora da escola, uma não tinha nada que vê. (JB8)

O segundo eixo temático Ações de enfrentamento da violência: possibilidades de intervir mostra algumas ações potencias para o enfrentamento dessa problemática, como estratégias de melhoria na educação e de maior investimento na família. Embora os participantes considerem difícil resolver o problema, ressaltam as normas de convívio social elaboradas pela direção da escola, e a inserção da discussão da temática em sala de aula por parte dos professores, como aspectos positivos. As falas a seguir confirmam a existência dessas ações:

[...] eu acho que não, a violência não tem como. Porque tu vai tentar prevenir ou evitar lá, sempre tem um ou outro que vai voltar e vai fazer tudo de novo. (JA3)

[...] é difícil, eu acho que a única forma de prevenir um pouco é na educação em casa mesmo, no mais é meio bem difícil, muito difícil. (JA1)

[...] a diretora, a direção sempre tá buscando,buscando assim, alguma coisa pra mostrar pros jovens que violência é ruim, que não é que não é pra eles isso. (JA2) 
[...] existe até os professores falaram. Até bastante sobre o bullying, foi bem interessante até, fizemos bastante trabalho. (JA3)

Observa-se o desejo pela presença de pessoas para auxiliar no enfrentamento da violência. Além disso, os adolescentes reconhecem que os equipamentos, como câmeras de vídeo nas escolas, também contribuem para diminuir as atitudes violentas nesse espaço, embora alguns declarem que o uso de câmeras não é uma medida efetiva. Essas recomendam mais diálogo entre professores e alunos, e mais acompanhamento de monitores no interior da escola, como se pode observar na fala a seguir:

[...] eu acho que câmera no colégio, por exemplo, é uma coisa que não adianta muita coisa. Mesmo que é difícil ver alguém o tempo todo cuidando as câmeras. Eu acho que tinha que ter só mais fiscalização de monitores e haver mais diálogo de professores com os alunos sobre a questão. (J3A)

Outro aspecto importante está relacionado às atitudes ao combate à violência na escola, as quais são representadas pela elaboração de normas de conduta e distribuídas pelos gestores aos adolescentes que devem segui-las e respeitá-las, e em caso de descumprimento recebem advertência, com punição e suspensão. Soma-se a isso a segurança pública, com a presença de policiais e do conselho tutelar, os quais são chamados pela direção da escola para controlar situações mais graves e dar encaminhamentos mais precisos. Essas medidas parecem ter sido adotadas por um período determinado, em que as violências severas estavam mais presentes, o que é confirmado nas seguintes falas:

[...] no recreio, eu acho, um piá pediu pra ficar com ela né, e a outra que era ex-namorada dele ficou com ciúme dai brigaram as duas. A escola chamou a polícia, sempre chamam a polícia. Quando tem briga. Esses tempos tinha polícia que ficava na hora da saída. Agora não, mas antes tinha. (JB1)

[...] a direção, assinam ata e suspensão. Chamam a polícia. A polícia vem e entra aqui [...]. Agora não tem mais polícia. (JB7)

[...] eles chamam, eles mandam assinar a ata, chamam os pais, até se o caso é muito grave eles expulsam da escola, dão suspensão por três dias, eles dão a maior força. Às vezes até chamam o conselho tutelar se a pessoa é menor [de idade], ou não, eles fazem. (JB8)

Pode-se observar que a escola, a segurança pública e o conselho tutelar atuaram unidos para combater a violência, reconhecendo os limites de cada campo diante dessa complexa problemática e a necessidade de se complementarem.

\section{DISCUSSÃO}

Iniciam-se as discussões mencionandoe que a violência aparece nas falas dos estudantes como algo comum e naturalizada, e as motivações para as brigas são banais - disputas por namorado(a), competições entre times esportivos, necessidade de autoafirmação, entre outros - e o ambiente escolar é o palco das brigas motivadas por essas banalidades, envolvendo professores e alunos. Constata-se, portanto, que a violência é considerada um acontecimento que se desenvolve naturalmente na vida, uma situação comum oriunda de causas banais ${ }^{(1)}$.

Ser temido e atrevido é uma representação do masculino, reforçada pelo conceito de gênero vigente na sociedade e no ambiente escolar pelos próprios jovens escolares que sobressaem e são respeitados pelas condutas violentas ${ }^{(5)}$. As brigas acontecem entre meninas, mas são mais frequentes entre os meninos ${ }^{(9)}$; as que ocorrem no meio feminino possuem certas características, representadas por tapas, arranhões e puxões de cabelo. As motivações das brigas também chamam a atenção, pois são consideradas motivações fúteis, como ciúmes, inveja, fofocas e disputa por namorados ${ }^{(5)}$.

De acordo com o estudo intitulado Revelando tramas descobrindo segredos: violência e convivência na escola ${ }^{(5)}$, realizado com alunos e professores do ensino fundamental e médio de escolas públicas do Distrito Federal, a violência no meio feminino tem tomado proporções maiores com o passar do tempo, mesmo que ainda haja predominância do sexo masculino nas atitudes agressivas. Essas condutas agressivas das mulheres devem ser consideradas significativas, principalmente quando atingem meninas no ambiente escolar. $\mathrm{O}$ estudo mostra as transformações que a feminilidade vem sofrendo com o passar do tempo, e diversos significados são atribuídos a essas mudanças: degradação dos valores morais femininos, expressão de um padrão feminino corrompido e, também, o empoderamento das mulheres ${ }^{(5)}$.

Quanto à característica da estrutura familiar e o 
comportamento violento das meninas a tendência é de que elas sejam mais agressivas quando residem com seus responsáveis do sexo masculino, o que pode estar relacionado ao modelo de resolução de conflito expressado historicamente pelo gênero masculino, fazendo-as reproduzir esse comportamento com seus pares. Soma-se a isso o fato de que as meninas mais agressivas convivem com irmãos mais velhos, os quais dão exemplos de atitudes violentas ${ }^{(10)}$. A forma como os pais e ou responsáveis pelos adolescentes se relacionam inspira a reprodução das condutas inadequadas pelos filhos, mostrando a forte influência das famílias no comportamento dos adolescentes. Quanto mais intensas forem as situações de violência familiar maior será a possibilidade desses comportamentos se estenderem aos pares e à escola ${ }^{(6)}$; a probabilidade da menina ser vítima ou agressora está relacionada à convivência em famílias cuja forma de comunicação é a violência, o que contraria a ideia de que só o menino é o agressor ${ }^{(10)}$.

Há bastante diferença entre o gênero feminino e masculino em relação à violência; as agressões físicas, o envolvimento em brigas com armas brancas e de fogo tem maior índice de prevalência entre o sexo masculino, mostrando que os meninos estão mais expostos à violência, o que pode ser explicado pela diferença dos papéis que há entre homens e mulheres, de como a sociedade e a cultura os caracteriza. A mulher sempre foi considerada delicada, frágil e pacífica, controladora de suas ações; o homem é associado a uma expressão de agressividade no meio social ${ }^{(9)}$.

Outro aspecto observado é que a violência vivida entre os adolescentes no espaço escolar pode ser levada para fora da escola, do mesmo modo que pode iniciar fora e vir para dentro do educandário, reforçando a ideia de que a violência está na sociedade e os limites entre os espaços fora e dentro são tênues. Além disso, as condições do entorno escolar também podem influenciar o surgimento da violência. Os homicídios, estupros, agressões com armas eram as mais graves formas de violência há algum tempo, estavam distantes, mas hoje estão presentes nas proximidades das escolas. Esses fatos projetam a impressão de que não existem mais limites, ou seja, que daqui para frente tudo pode acontecer na escola, contribuindo para produzir a angústia social face à violência escolar ${ }^{(11)}$.

Trazer para a sala de aula discussões sobre a temática bullying são iniciativas relevantes. Estudo realizado em Lisboa - Portugal revela que houve considerável redução de comportamentos violentos após a implantação de programa de prevenção ao bullying na escola. Anteriormente à implantação do programa, os alunos agredidos revidavam com outra agressão ou ocultavam a situação, demonstrando que, além de causar sofrimento, o bullying também pode tornar-se um ato silencioso, sendo difícil de ser identificado ${ }^{(9)}$.

Estudo constatou que as atividades educativas proporcionam aos adolescentes o conhecimento de outros tipos de violência que ocorrem no seu cotidiano escolar, demonstrando que a informação auxilia a formação do pensamento crítico do indivíduo e a conscientização para o combate à violência na escola, pois o adolescente, podendo identificar os praticantes dos atos violentos, faz com que a intervenção da escola, da saúde ou de qualquer outro setor possa ser mais efetiva ${ }^{(12)}$.

A escola que procura promover novas metodologias de prevenção à violência precisa iniciar o processo de inclusão da família nas atividades escolares. Sabe-se que o ambiente familiar interfere diretamente no comportamento do adolescente, e é importante que a família se torne parceira na construção de novas formas que potencializem a educação, que esteja presente nas tomadas de decisão da escola, que as reuniões contenham dinâmicas que incentivem os pais a participarem das atividades do ambiente escolar, que os pais percebam a sua responsabilidade em relação à educação dos filhos dentro da escola, e o quanto essa participação é importante na prevenção da violência ${ }^{(6)}$. A recuperação do diálogo na família também é uma conduta necessária para prevenir a violência ${ }^{(13)}$.

A presença de supervisores nos espaços de recreio, acompanhando os adolescentes, coíbe atitudes violentas. $\mathrm{O}$ agressor se intimida e a vítima sente-se protegida, diminuindo os níveis de bullying ${ }^{(10)}$, sobretudo porque os locais da escola em que mais ocorre a violência, além dos limites externos, são o pátio, corredores, quadra de esportes, salas de aula, banheiro e refeitórios; e os horários são os da saída, recreio, aulas, atividade na escola fora do horário das aulas e antes do início das aulas ${ }^{(5)}$.

Os adolescentes destacam que o diálogo possui o poder de prevenir a violência; mesmo que muitas pessoas ainda não acreditem que esse método de prevenção seja eficiente e a forma mais correta de resolver conflitos $^{(14)}$.

O diálogo e o respeito entre professores e alunos é uma medida sugerida como facilitadora das relações. Já, o autoritarismo dos professores faz com que o alunos se afastem e impede o estabelecimento de uma relação de confiança. As atitudes de violência verbal, 
humilhação e discriminações em sala de aula por parte dos professores contribuem para a baixa autoestima dos alunos e, consequentemente, para a queda no aprendi$z$ ado $^{(4)}$. Nessa direção, recomenda-se que se crie um novo modelo de relação entre professor e aluno com maior elasticidade e tolerância, implicando construção de um novo conceito de disciplina como componente para o processo de aprendizagem ${ }^{(3)}$.

A complexidade da violência exige que os serviços de educação, segurança, defesa e proteção atuem de forma conjunta e interssetorial, permitindo a flexibilidade e a ampliação do fluxo em todas as dimensões do cuidado $^{(15)}$. Dessa forma, um trabalho organizado em rede pode otimizar ações de intervenção à violência em cada setor, permitindo assistência mais próxima do adolescente e da família, podendo acontecer nas Unidades Básicas de Saúde da Família pela condução de grupos de reflexão com as famílias, nas escolas e centros de Educação Infantil ${ }^{(16)}$.

A escola tem o papel de auxiliar o desenvolvimento das relações interpessoais, as capacidades físicas e morais do indivíduo, por meio das ações educativas. $\mathrm{Na}$ maioria das instituições escolares, geralmente, existem regras aplicadas ao cotidiano, relacionadas à assiduidade, uso do uniforme e as práticas permitidas ou proibidas no ambiente escolar. Algumas podem ser mais flexíveis que outras ${ }^{(1,3)}$, no entanto, é um local em que ocorrem conflitos e brigas com manifestações físicas de agressividade, e para controlar essa violência, a direção escolar adota instrumentos mais rigorosos advertências, suspensões, transferências e expulsões, de acordo com a gravidade do caso. A prática da punição é um dos componentes para modelar condutas e minimizar a violência, mas é preciso refletir que a adoção dessa estratégia tanto pode promover comportamentos conformados como revoltar os alunos e gerar novas formas de violência ${ }^{(1,3)}$.

A participação ativa da família no ambiente escolar constitui importante contribuição para a prevenção da violência nas escolas e poderá facilitar as relações de convívio em casa, pois a família é o espaço em que o adolescente procura apoio nos direcionamentos das suas escolhas da vida, é onde ele possui os exemplos para a convivência na sociedade. Para que a família esteja mais presente na educação dos filhos, e sirva de parceira da escola no combate à violência, é necessário que a escola repense novos métodos para aproximar-se dos membros da família, o que contribuirá para a construção de um ambiente escolar mais saudável e menos violento ${ }^{(7)}$.
É preciso entender que a violência está presente na comunidade, a qual deve chamar as pessoas à participação para enfrentar a violência em uma ação conjunta com a escola e, nesse aspecto, as lideranças comunitárias se tornam importantes aliadas ao combate à violência. Observa-se grande dificuldade das comunidades em assumir a existência de violência nos bairros, e os grupos mais bem organizados têm percepção mais ampliada e complexa da violência que engloba a exclusão, pobreza, desigualdade social e corrupção $0^{(17)}$.

Convidar outros profissionais para atuar nas intervenções de enfrentamento da violência na escola é necessário, considerando-se a importância de outras opiniões para gerar uma discussão fundamentada e concreta sobre o tema e que auxilie a buscar novas estratégias de intervenção. Dessa forma, é importante investir em pesquisas e intervenções que auxiliem a criar novas políticas públicas, eficazes na prevenção e diminuição da violência na escola. Sugere-se a abordagem interdisciplinar, com diversas áreas do conhecimento, entre as quais a terapia ocupacional, pedagogia, artes e comunicação, em oficinas e atividades lúdicas com recursos audiovisuais e diálogo para melhorar a aproximação com os adolescentes e fortalecer o vínculo com os profissionais. Mesmo que a inserção de outros profissionais na prevenção da violência na escola ainda seja um desafio, é necessário que se invista em intervenções interdisciplinares e intersetoriais para buscar novas perspectivas de ações de combate à violência na escola, e que as universidades possam proporcionar a formação de profissionais comprometidos com as questões sociais ${ }^{(18)}$.

\section{CONSIDERAÇÕES FINAIS}

Apesar da descrença nas ações de prevenção, os adolescentes percebem a possibilidade de enfrentamento da violência na escola por meio de ações de melhoria na educação, e em casa com maior investimento na família; valorizam as normas e regras de convivência na escola, a inclusão de temas relacionados à violência na escola - bullying por parte de alguns professores, câmaras para vigilância e a intervenção da Segurança Pública e Conselho Tutelar; clamam pela inclusão de mais assistentes (monitores) e professores na escola e maior diálogo com os professores.

Os resultados deste estudo mostram a necessidade de maior investimento por parte do poder público em ações que mantenham as famílias mais próximas da es- 
cola, dando oportunidade de educação, trabalho, remuneração, saúde e lazer visando transformar o ambiente familiar, tornando-o o menos vulnerável possível.

Criar ambientes mais seguros e agradáveis nas escolas, comunidades e sociedade é responsabilidade do poder público em suas três esferas de governo cujas ações baseiam-se na intersetorialidade e participação coletiva, em que a educação para a paz e o estímulo a atitudes positivas entre os integrantes da comunidade escolar seja o caminho a ser seguido.

Recomenda-se maior suporte do Estado à instituição escolar com incentivo à qualificação profissional dos integrantes da escola para adquirir competências a fim de superar os conflitos existentes entre os seres humanos que podem ser resolvidos pelo diálogo. Além disso, reforçar uma forma de trabalho intersetorial com a inserção de parceiros - o setor saúde, de segurança, da justiça e órgãos protetores da juventude.

A implementação de políticas sociais que visem promover condições de vida às famílias dos escolares - acesso ao trabalho, habitação, cultura, qualificação profissional, remuneração mínima, serviços de saúde, lazer - poderá contribuir para amenizar as situações de vulnerabilidade e violência social, familiar e escolar.

\section{REFERÊNCIAS}

1. Abramovay M, Rua MG. Violência nas Escolas. Brasília: UNESCO; 2002.

2. Priotto EP, Boneti LW. Violência Escolar: na escola, da escola e contra a escola. Rev. Diálogo Educ. 2009;9(26):161-79.

3. Ruotti C. Violência em meio escolar: fatos e representações na produção da realidade. Rev. Educ. Pesqui. 2010;36(1);339-55.

4. Eyng AM, Gisi ML, Ens RT. Violência nas Escolas e Representações Sociais: um diálogo necessário no cotidiano escolar. Rev Diálogo Educ. 2009;9(28):476-80.

5. Abramovay M. (coord). Revelando tramas, descobrindo segredos: violência e convivência nas escolas. Rede de Informação Tecnológica Latino-americana - RITLA, Secretaria de Estado de Educação do Distrito Federal - SEEDF. Brasília; 2009.

6. Tortorelli MFP, Carreiro LRR, Araújo MV. Correlações entre a percepção da violência familiar e o relato de violência na escola entre alunos da cidade de São Paulo. Psicol. Teor. Prat. 2010;12(1):32-42.
7. Mendes CS. Prevenção da Violência Escolar: avaliação de um programa de intervenção. Rev Esc Enferm USP 2011;45(3):581-88.

8. Minayo MCS. O desafio do conhecimento: pesquisa qualitativa em saúde. 8 ed. São Paulo: Hucitec; 2007.

9. Malta DC, Souza ER, Silva MMA, Silva CS, Andreazzi MAR, Crespo C et al. Vivência de violência entre escolares brasileiros: resultados da Pesquisa Nacional de Saúde do Escolar (PeNSE). Ciênc. saúde colet. 2010;15(supl 2):3053-63.

10. Silva KL, Dias FLA, Vieira NFC, Pinheiro PNC. Reflexões acerca do abuso de drogas na adolescência. Esc. Anna Nery. 2010;14(3):605-10.

11. Charlot B. A violência na escola: como os sociólogos franceses abordam essa questão. Sociologias. 2002;4(8):432-43.

12. Silva KL,Dias FLA, Vieira NFC, Pinheiro PNC. Reflexões acerca do abuso de drogas na adolescência. Esc. Anna Nery. 2010;14(3):605-10.

13. Frota MA, Nogueira JLA, Bezerra LLAL, Lima PRF, Filhos OAS, Costa RO.Percepção das crianças da periferia de Fortaleza -Ceará acerca da Violência. Cogitare enferm. 2010;15(3): 427-32.

14. Malta DC, Silva MAI, Mello FCM, Monteiro RA, Sardinha LMV, Crespo C et al. Bullying nas escolas brasileiras:resultadosdaPesquisaNacionaldeSaúdedoEscolar (PeNSE), 2009. Ciênc. saúde colet. 2010;15(supl 2):3065-76.

15. Ministério da Saúde (BR). Linha de Cuidado para Atenção Integral à Saúde de Crianças, Adolescentes e suas Famílias em Situação de Violências: Orientação para Gestores e Profissionais da Saúde. Secretaria da Atenção à Saúde. Departamento de Ações Programáticas Estratégicas. Brasília; 2010.

16. Oliveira BRG, Thomazine AM, Bittar DB, Santos FL, Silva LMP, Santos RLR et al. A violência intrafamiliar contra a criança e o adolescente: o que nos mostra a literatura nacional Reme. 2008;12(4):547-56.

17. Amaro MCP, Andrade SM, Garanhani ML. A Violência sob o olhar de lideranças comunitárias de Londrina, Paraná, Brasil. Saúde Soc. 2010;19(2);302-9.

18. Lopes RE, Adorno RCF, Malfitano APS, Takeiti BA, Silva CR, Borba PLO. Juventude pobre, violência e cidadania. Saúde Soc. 2008;17(3):63-76. 